\title{
Effect of breast-feeding patterns on human birth intervals*
}

\author{
P. W. Howie $†$ and A. S. McNeilly \\ M.R.C. Unit of Reproductive Biology, University of Edinburgh, Centre for Reproductive \\ Biology, 37 Chalmers Street, Edinburgh EH3 9EW, U.K.
}

An adequate inter-birth interval is of great importance because it enables a mother to recover her physical and emotional strength between pregnancies and confers upon the child advantages of better health and development (Morley, 1977). Breast feeding is the naturally evolved method of ensuring an adequate inter-birth interval but the contraceptive effect of breast feeding has been largely dismissed in developed countries on the grounds that it is an unreliable method of family planning for individual mothers (Kamal et al., 1969). The use of artificial contraception varies very widely in different countries, being much higher in developed nations than in the poorer developing countries (Text-fig. 1). Where the use of artificial contraceptives is low, breast feeding is the most widely used method of birth spacing and assumes major demographic importance. It is important, therefore, that the factors controlling lactational infertility should be understood so that guidelines can be developed which will allow mothers to maximize the birth-spacing effect of breast feeding to their own advantage. In developed countries, few mothers choose to rely on breast feeding for family planning although an increasing minority may find breast feeding to be an attractive method of spacing their families, thereby avoiding the potentially adverse side-effects of currently available contraceptive methods. A better understanding of how breast feeding mediates its birth-spacing effect may lead to the development of new contraceptive methods which will try to imitate this naturally evolved method of fertility control (McNeilly, 1979).

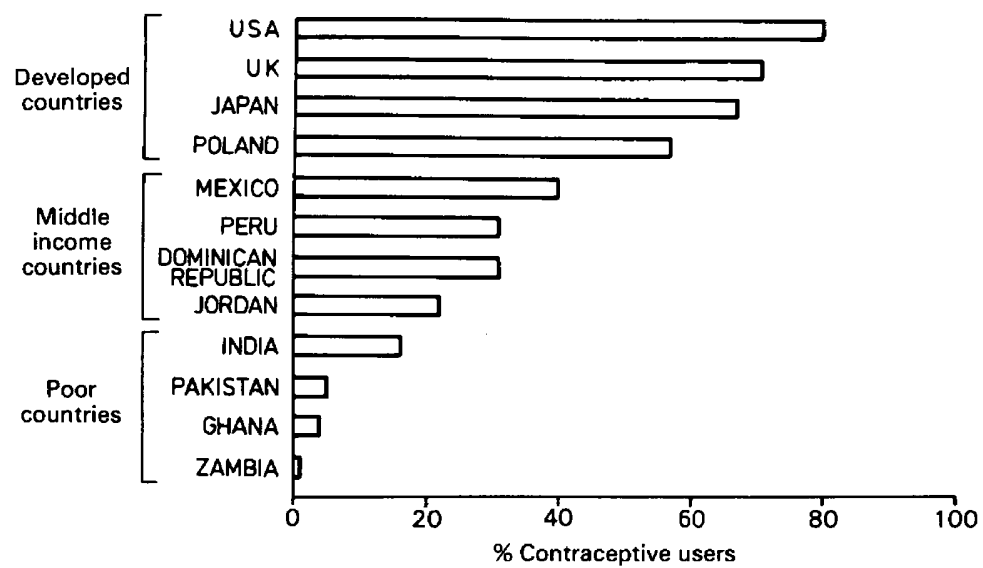

Text-fig. 1. Contraceptive usage by married women aged $15-44$ years in different countries by economic status. Source: Population Reference Bureau Inc. Washington D.C., U.S.A.

* Reprint requests to: Dr A. S. McNeilly.

$\dagger$ Present address: Department of Obstetrics \& Gynaecology, Ninewells Hospital and Medical School, University of Dundee, Dundee, U.K. 
This paper will describe the methods which have been used to investigate lactational infertility and discuss how different breast-feeding patterns influence human birth intervals.

\section{Methods of assessing lactational infertility}

Lactational infertility can be measured in three different ways: (1) by the duration of the interbirth interval, (2) by the duration of lactational amenorrhoea and (3) by the return of ovulation. These methods present different problems of interpretation and a complete picture of lactational infertility can only be achieved by considering all the information which has been gathered from these different sources.

Interbirth interval. The ultimate test of fertility is pregnancy and several reports have demonstrated that breast feeding increases the interval between pregnancies (for summary, see van Ginneken, 1977). For example, two studies compared the time to next conception in nursing and non-nursing mothers from Alaskan Eskimo (Berman, Hanson \& Hellman, 1972) and rural Indian populations (Potter, New, Wyon \& Gordon, 1965). Despite the wide differences in climate and culture, the conception rates were similar in the two populations and conception occurred sooner in the non-lactating than lactating mothers (Text-fig. 2). Considering the time until $50 \%$ of the mothers conceived again, breast-feeding conferred an additional fertility protection of 14 months in the Indian women and 10 months in the Eskimo women; assuming that these intervals repeated themselves between successive pregnancies, this would mean that non-nursing women would have almost double the number of children than the breast feeding women over the same time period.

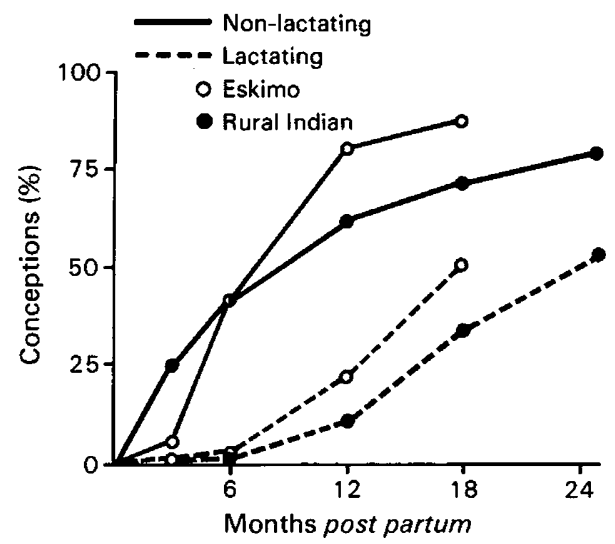

Text-fig. 2. Cumulative conception rates since last pregnancy in lactating and non-lactating mothers. Data for Eskimos from Berman et al. (1972), Indian rural from Potter et al. (1965).

Rosa (1975) has attempted to quantify the contraceptive effect of breast feeding in developing countries and has compared its contribution to fertility protection with that of artificial contraceptives. Assuming additional fertility protection of 8 months in rural mothers and of 4 months in urban mothers, Rosa (1975) estimated that, in the course of 1 year, breast feeding contributed over $31 \times 10^{6}$ couple years of contraceptive protection; by comparison, the known sales of artificial contraceptives contributed $24 \times 10^{6}$ couple years of fertility protection over the same time period. Knodel (1977) has pointed out that the demographic consequences of breast feeding are complex because the contraceptive effects of breast feeding on population growth are reduced, at least to some extent, by the lower mortality rates among breast fed babies. There can be no doubt, however, that breast feeding has profound implications in developing countries both for the individual mother and for the population as a whole. 
Despite the clear evidence that breast feeding is associated with prolonged interbirth intervals, it cannot be assumed that breast feeding per se is directly responsible for this effect. In many cultures, particularly in Africa, sexual taboos are imposed on nursing mothers and reduced frequency of intercourse could explain, at least in part, the fertility-inhibiting effect of breast feeding. Contraceptive practices during lactation could also influence the interbirth interval and the use of coitus interruptus, for example, cannot be monitored on the basis of contraceptive marketing figures. An example of how behavioural factors can influence the interbirth interval was demonstrated by Chen, Ahmed, Gesche \& Mosley (1974) during their detailed prospective study in Bangladesh. They found that the conception rates after the return of post-partum menses were lower in fishermens' wives than in farmers' wives, probably because the fishermen were absent from home for longer periods. It is essential, therefore, to know what behavioural variables might influence the interbirth interval before the epidemiological evidence of more prolonged birth spacing can be directly attributed to breast feeding itself.

Lactational amenorrhoea. The return of menstruation post partum has been used in many studies as an indirect index of resumed ovulation (see van Ginneken, 1977). This method is convenient because it is easy to measure and can be applied to large populations. Many studies have shown that the duration of post-partum amenorrhoea is longer in nursing than non-nursing mothers (for summary, see Buchanan, 1975). In non-nursing mothers, the duration of post-partum amenorrhoea averages about 3 months, but among nursing mothers it may last for more than 2 years. It is also clear that fertility is markedly reduced during the period of lactational amenorrhoea. Chen et al. (1974) calculated that, during 18 months of lactational amenorrhoea in Bangladesh, the pregnancy rate was less than 5 per 100 women years of exposure which compared well with many artificial contraceptive methods. The duration of lactational amenorrhoea is much longer in rural than in urban communities (van Ginneken, 1977) because rural mothers breast feed more intensively and for a longer time.

Much valuable information has been gathered from the study of lactational amenorrhoea but its validity depends upon the assumption that the capacity of breast feeding to prevent pregnancy is limited to the duration of lactational amenorrhoea. It is well known that breast feeding does not postpone pregnancy indefinitely and $2-10 \%$ of mothers conceive during the period of lactational amenorrhoea (Badraoui \& Hefnawi, 1979). There is also evidence (see below) that the fecundity of breast feeding women does not return to normal after the return of menses post partum. It is, therefore, desirable to have information from studies which directly measure the resumption of ovulation during the post-partum period.

Detection of ovulation. Most studies which have attempted to define the timing of ovulation after childbirth have used endometrial biopsy (Lass, Smelser \& Kurzrok, 1938; Topkins, 1943; Udesky, 1950; El-Minawi \& Foda, 1971), basal body temperature (Sharman, 1951; Cronin, 1968), cervical mucus or vaginal cytology (Perez, Vela, Masnick \& Potter, 1972) as markers of ovulation but these methods present problems of interpretation. During lactation, the histology of the endometrium may show inadequate co-ordination of maturation signs characteristic of the normal menstrual cycle, making it difficult to determine whether ovulation has occurred (El-Minawi \& Foda, 1972). Ideally, endometrial biopsies should be taken in the pre-menstrual phase and, in the absence of regular menstrual cycles, the correct timing of biopsies can be difficult to achieve. Biopsies taken on the first day of bleeding, as happened in several studies, may be unreliable markers of ovulation. Temperature charts during lactation may show a much shorter plateau in the pre-menstrual phase (Cronin, 1968) making precise interpretation difficult.

As an alternative to these methods, the use of plasma or urinary steroid concentrations provides objective evidence of ovulation and enables a quantitative estimate of menstrual cycle adequacy. Rolland, Lequin, Schellekens \& de Jong (1975) used plasma steroid levels to show that ovulation returned more quickly in mothers who discontinued breast feeding early in the puerperium but the studies were not continued beyond 100 days post partum. Urinary total oestrogen and pregnanediol excretion can be used to monitor ovarian follicular activity and 
ovulation (McNeilly, Howie \& Houston, 1980) and this non-invasive method has enabled us to monitor 10 bottle-feeding and 27 breast-feeding mothers from delivery until first ovulation.


Text-fig. 3. Return of ovarian activity (urinary total oestrogens $>10 \mu \mathrm{g} / 24 \mathrm{~h}$ ) and ovulation (urinary pregnanediol $>1 \mathrm{mg} / 24 \mathrm{~h}$ ) in the early puerperium in a bottle feeding mother.
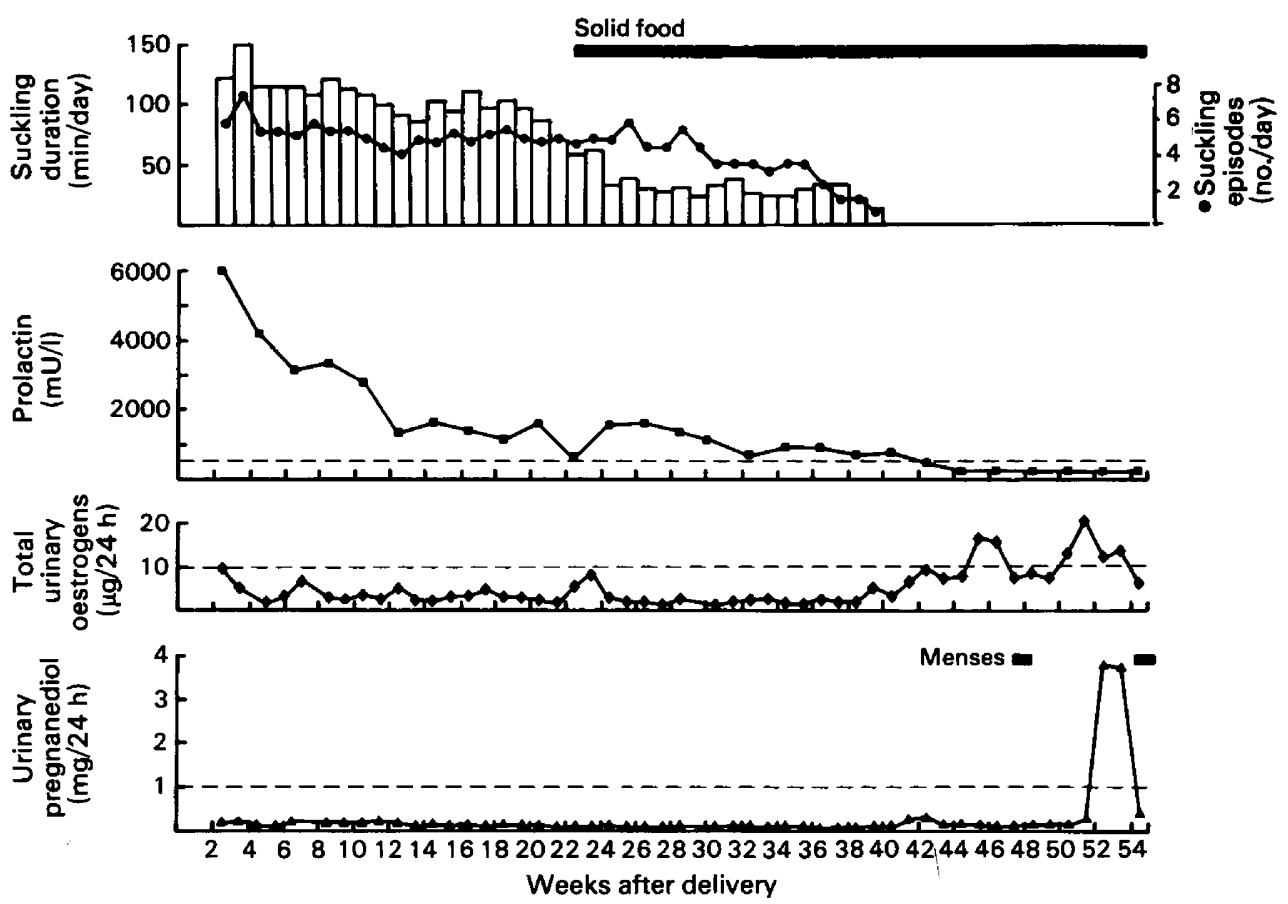

Text-fig. 4. Delayed return of post-partum ovarian activity and ovulation in a breast-feeding mother. 
The inhibitory effects of breast feeding are illustrated by the pattern of endocrine events leading to the resumption of ovulation in a typical bottle feeding (Text-fig. 3) and a typical breast feeding (Text-fig. 4) mother. In the bottle-feeding mother, basal prolactin levels had returned to the non-pregnant range within 4 weeks post partum and this was followed by an early resumption of ovarian follicular activity (total urinary oestrogens $>10 \mu \mathrm{g} / 24 \mathrm{~h}$ ) and menstruation. Ovulation (urinary pregnanediol $>1 \mathrm{mg} / 24 \mathrm{~h}$ ) did not occur during the first cycle but resumed in the second and third cycles. In the breast-feeding mother, basal prolactin levels fell progressively as suckling duration was reduced but remained above the non-pregnant range until the cessation of breast feeding at 40 weeks post partum. Ovarian activity and ovulation were suppressed until 44 weeks post partum when the first anovulatory cycle was followed by menstruation at 47 weeks. After the first post-partum cycle, there was an interval of 7 weeks before the next menstruation which was followed by a normal ovulatory cycle.

Considering the time of first ovulation in the total group of 10 bottle-feeding and 27 breast-feeding mothers, the bottle feeders ovulated between 6 and 15 weeks post partum compared with 15-68 weeks in the breast feeders. This finding is consistent with previous reports (Udesky, 1950; Sharman, 1951; Cronin, 1968; Perez et al., 1972) and indicates that a major part of the antifertility effect of breast feeding can be attributed to the inhibition of ovarian follicular development and ovulation.

\section{Components of the interbirth interval}

The interbirth interval consists of three phases, the phase of lactational amenorrhoea, the menstruating interval (which is the interval between the return of post-partum menstruation and next conception) and the length of gestation itself. Only the period of gestation is relatively fixed, the durations of lactational amenorrhoea and the menstruating interval varying widely between populations and between individuals within these populations. It is, therefore, important to consider the timing and frequency of ovulations during lactational amenorrhoea and during the menstruating interval.

Ovulation during lactational amenorrhoea. As previously discussed, fertility is substantially reduced during the phase of lactational amenorrhoea but between 2 and $10 \%$ of nursing mothers conceive before first post-partum menstruation. This is an important practical point because it means that the return of menstruation cannot be used as an indication of when to resume contraception.

Using endometrial biopsy as a marker of ovulation, Udesky (1950) reported that ovulation during lactation was followed either by menses or by pregnancy. This finding has been supported by our own studies (Howie, McNeilly, Houston, Cook \& Boyle, 1981) and indicates that recurrent ovulations do not take place throughout the phase of lactational amenorrhoea. There is some dispute about the frequency of ovulation in the cycle before the end of lactational amenorrhoea, the estimates varying from 14\% (Udesky, 1950), 23\% (Cronin, 1968) and 33\% (Howie et al., 1981) to 75\% (Perez et al., 1972). The different estimates of ovulation frequency during lactational amenorrhoea may be partly explained by the different methods used to assess ovulation but are more likely to be due to the different suckling patterns of the populations studied. It has been shown that the longer that the first menses is delayed during lactation, the more likely is the first cycle to be ovulatory (Perez et al., 1972; Howie et al., 1981). The impact of different suckling patterns upon post-partum ovulation is discussed below.

Ovulation during the menstruating interval. There is less information about the frequency of ovulation in breast feeding mothers who have resumed menstruation and it has been suggested that the capacity of prolonged breast feeding to prevent pregnancy is limited to the period of lactational amenorrhoea. Several strands of evidence suggest, however, that fecundity is reduced 
during the menstruating interval. Chen et al. (1974) studied the conception rates after the return of post-partum menses in nursing mothers and found that they were much lower than would be expected in a non-nursing group of women (Tietze, 1968) who were not using contraception (Text-fig. 5). Similarly, Potter et al., 1965) found pregnancy rates of 22 and $32 \%$ in nursing mothers at 3 and 6 months after first menses compared with corresponding figures of 39 and $47 \%$ in mothers who experienced a neonatal death. During the menstruating interval, the frequency of anovulatory cycles increased, being estimated at 55\% (Lass et al., 1938) and $42 \%$ (Howie et al., 1981). Reduced fecundity amongst nursing mothers is further supported by the increased intervals between menstrual periods, compared with cycles in non-nursing mothers (Sharman, 1951; Berman et al., 1972; Howie et al., 1981), which suggests a disturbance of normal rhythms during lactation.

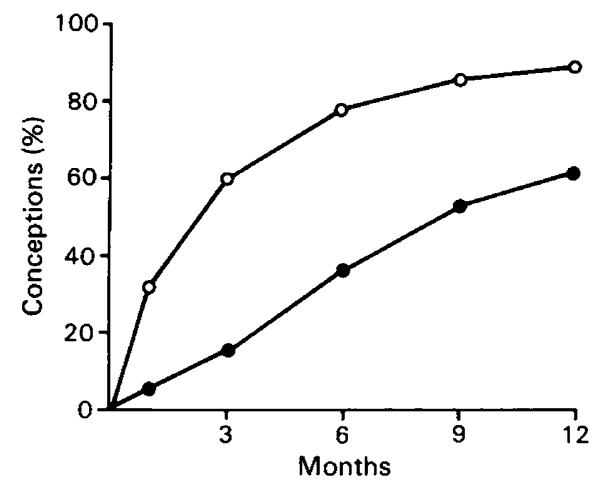

Text-fig. 5. Conception rates in (e) nursing mothers after the return of post-partum menses (Chen et al., 1974) and in (O) non-nursing women using no contraception (Tietze, 1968).

Using plasma steroid concentrations as a marker of ovulation, Duchen \& McNeilly (1980) found a lower incidence of ovulatory cycles during lactation than would be expected in a normal population. An example of an individual mother who had recurrent anovulatory cycles during lactation is shown in Text-fig. 6. After the introduction of solid food, basal prolactin levels

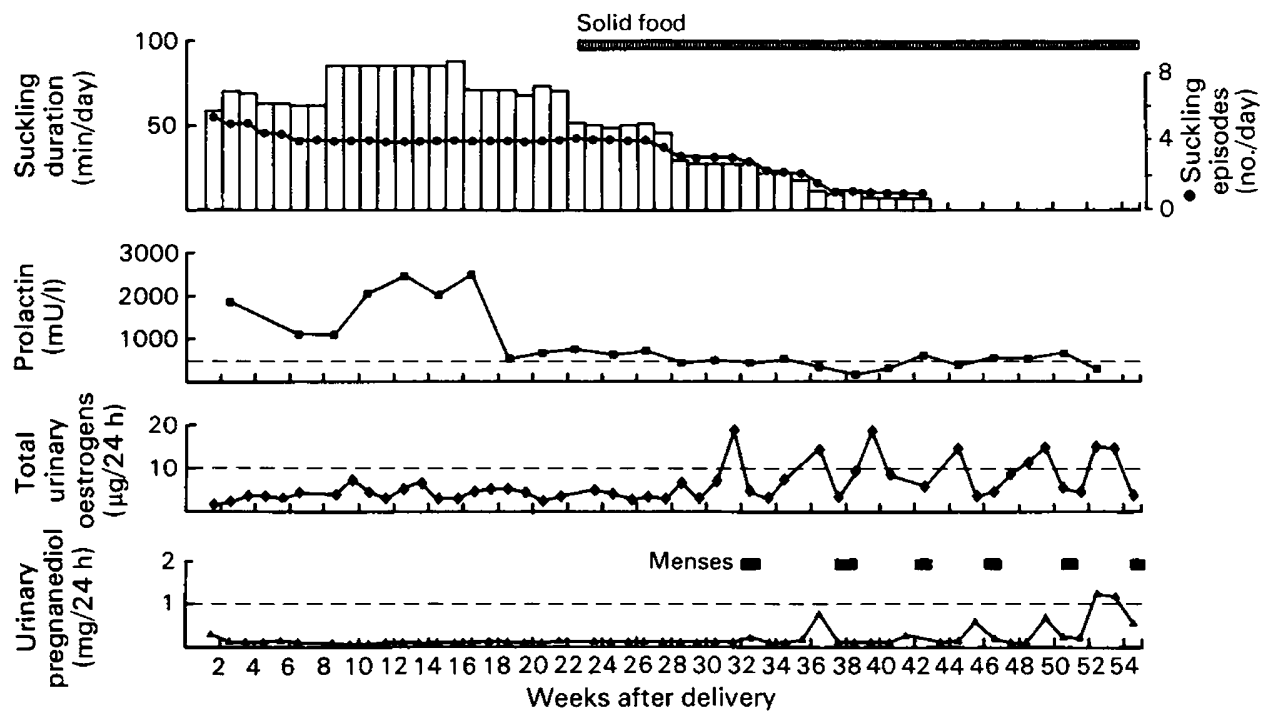

Text-fig. 6. Anovulatory cycles in a breast-feeding mother during lactation. 
returned to the pregnant range and there were 5 anovulatory cycles (urinary pregnanediol $<1$ $\mathrm{mg} / 24 \mathrm{~h}$ ) before ovulation resumed after complete weaning. We have studied the levels of urinary steroid excretion in 54 cycles during lactation and compared them with the levels in 30 cycles after lactation and 27 cycles in non-pregnant controls (Text-fig. 7). During lactation, the mean ( \pm s.e.m.) level of urinary pregnanediol in the luteal phase were $0.93 \pm 0.09 \mathrm{mg} / 24 \mathrm{~h}$ which was significantly lower than the mean level of $1.62 \pm 0.15 \mathrm{mg} / 24 \mathrm{~h}$ in cycles after lactation and $2.13 \pm 0.83 \mathrm{mg} / 24 \mathrm{~h}$ in the non-pregnant controls. These results suggested a high incidence of cycles which were either anovular or characterized by inadequate luteal phases. Levels of total urinary oestrogen excretion (calculated as the mean of the 4 levels throughout the cycle) were $10.3 \pm 1.0 \mu \mathrm{g} / 24 \mathrm{~h}$ in cycles during lactation, $12.2 \pm 1.3 \mu \mathrm{g} / 24 \mathrm{~h}$ in cycles after lactation and $14.1 \pm 1.7 \mu \mathrm{g} / 24 \mathrm{~h}$ in cycles from non-pregnant controls. This was consistent with the hypothesis that the defective luteal function might have its origins in abnormal follicular development (McNeilly et al., 1980).

(a)

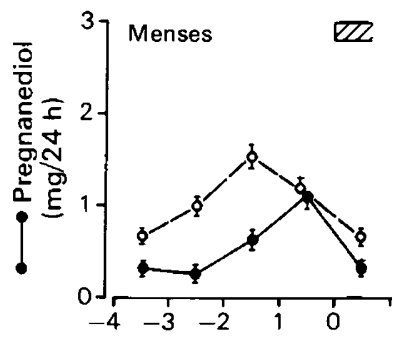

(b)

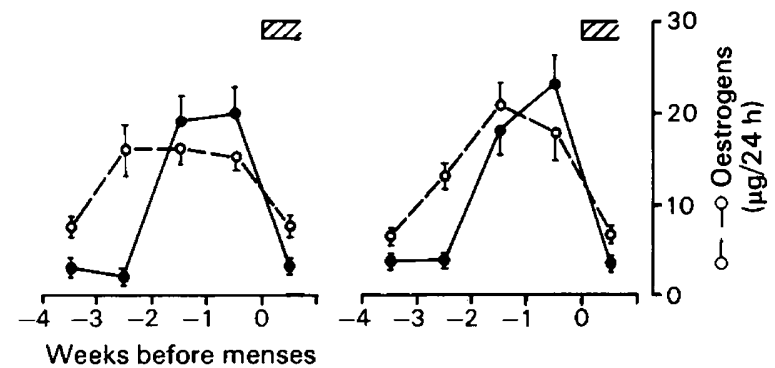

Text-fig. 7. Excretion of urinary total oestrogen and pregnanediol in menstrual cycles (a) during lactation $(n=54)$, (b) after lactation $(n=30)$ and (c) in non-pregnant controls $(n=27)$.

Values are mean \pm s.e.m.

The combined evidence suggests that the menstruating interval is associated with a reduction of fecundity which, however, is less complete than it is during the phase of lactational amenorrhoea.

\section{Effect of suckling upon fertility}

It is important to understand the effect which different suckling patterns have upon the restoration of fertility so that appropriate advice can be given to nursing mothers who wish to prolong the interbirth interval for as long as possible. It is well known that the phase of lactational amenorrhoea is much shorter during partial as compared with full (unsupplemented) breast feeding (Sharman, 1951; McKeown \& Gibson, 1954; Perez et al., 1972; Chen et al., 1974). Gioiosa (1955) reported that, out of 500 birth intervals in mothers who breast fed, 46 (9.2\%) conceived during lactation but 40 of these $(87 \%)$ conceived when the weaning process was taking place. Gioiosa (1955) concluded that the fertility protection associated with breast feeding lasted for 9 months or more, provided that no additional supplementary or complementary formula was used.

It is clear, therefore, that suckling is a major variable in the control of post-partum ovulation but relatively few studies have attempted to measure the suckling stimulus. Konner \& Worthman (1980) have reported that the prolonged interbirth intervals of up to 4 years among the nomadic !Kung hunter gatherers are associated with very frequent suckling bouts, which last for only 2 min every $15 \mathrm{~min}$. This suggests that very frequent suckling exerts a profound inhibitory effect upon reproduction. 
In Rwanda, rural women breast feed on demand and $50 \%$ conceive again within 23 months after delivery; by contrast, in urban women, breast feeding is operated on a more rigid schedule with fewer feeding episodes and $50 \%$ of mothers have conceived again within 9 months post partum (Bonte, Akingeneye, Gashakamba, Nbarutso \& Nolens, 1974). In a series of cross-sectional studies, Delvoye, Badawi, Demaeged \& Robyn (1978) found that prolactin levels were related both to the duration of lactational amenorrhoea and to the frequency of suckling. By extrapolation, these data suggest that the duration of lactational amenorrhoea is related to the pattern of suckling frequency. These various studies point to the profound effect which different suckling patterns exert upon post-partum fertility.

Infant feeding patterns and the time of first ovulation. From our own prospective studies, the infant feeding patterns were compared between mothers who ovulated before 30 weeks post partum, those who ovulated between 30 and 40 weeks post partum and those who ovulated after 40 weeks post partum. The mothers who postponed ovulation for longest ( $>40$ weeks) had a longer total duration of breast feeding than did those in the other two groups, but there were other differences between the groups as illustrated in Text-fig. 8; the mothers who ovulated after 40 weeks maintained suckling duration and frequency at the highest levels, introduced supplementary food most slowly and maintained night feeds for longest. The maintenance of night feeds (defined as a suckling episode between midnight and 08:00 h) may be important because a long interval without suckling could allow the hypothalamic-pituitary-ovarian axis sufficient time to recover and resume ovulation. This study suggested strongly that there was an inverse relationship between the use of supplementary foods and the strength of the suckling stimulus, and that the early and abrupt introduction of supplements might play an important part in relation to the resumption of post-partum ovarian activity and ovulation.
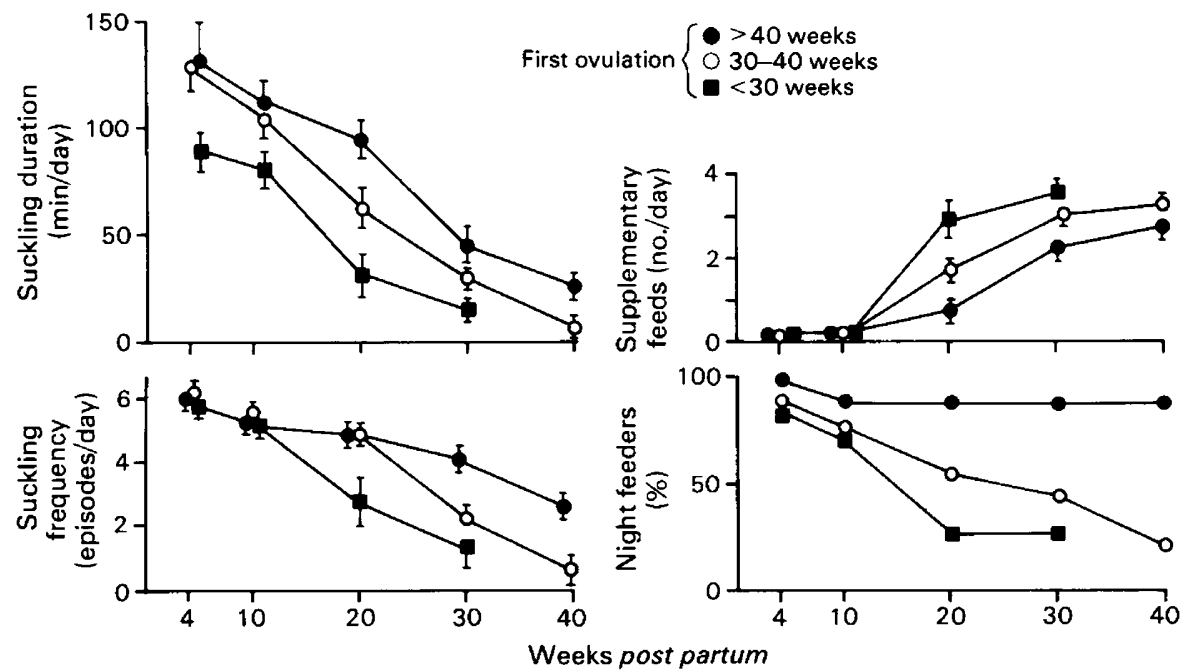

Text-fig. 8. Comparison of infant feeding in mothers ovulating before 30 weeks $(N=7)$, between 30 and $40(N=9)$ and after 40 weeks $(N=9)$ post partum. Values are mean \pm s.e.m.

Effect of supplementary food on suckling and ovulation. The critical importance of supplementary food was emphasized by centring the levels of suckling frequency and suckling duration round the time at which supplements were introduced (Text-fig. 9). Suckling duration and suckling frequency for the whole cohort of breast-feeding mothers remained relatively constant until supplements were given, after which both fell abruptly. These changes in suckling were reflected in the basal prolactin concentrations and, before the introduction of supplements, no mother had ovulated although four had evidence of ovarian follicular development. After 
supplements, progressively more mothers had evidence of ovarian follicular development and $52 \%$ had ovulated within 16 weeks of introducing supplementary food.

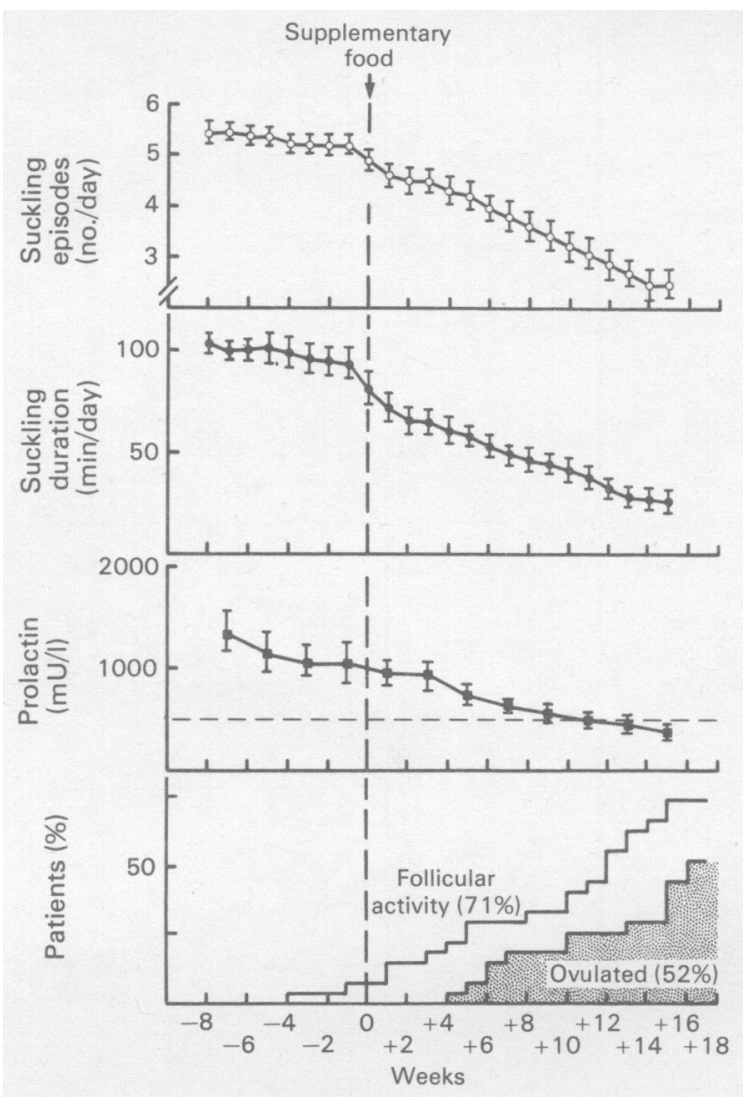

Text-fig. 9. Mean suckling duration, suckling frequency, basal prolactin and ovarian activity in women $(\mathrm{N}=27)$ before and after the introduction of supplementary food. Values are mean \pm s.e.m. Broken line indicates upper limit for non-pregnant women. (From Howie et al., 1981.)

In Text-fig. 10, the feeding patterns in the $52 \%$ who ovulated within 16 weeks of introducing supplements are compared with the $48 \%$ who continued to suppress ovulation over that time. The mothers who ovulated reduced suckling more rapidly and weaned more abruptly. The stronger suckling stimulus amongst those who continued to suppress ovulation was reflected in higher mean basal prolactin levels which remained above the non-pregnant range.

\section{Sequence of events leading to post-partum ovulation}

From the data presented in this paper, it is possible to formulate a hypothesis of the events leading to the return of post-partum ovulation. In bottle-feeding mothers, plasma prolactin concentrations return to normal within a few weeks of delivery and there is an early resumption of ovarian activity and ovulation. In breast-feeding mothers, prolactin values are elevated and ovarian function is suppressed, the extent of that suppression being dependent upon the strength and duration of suckling; the suckling stimulus is undermined by the use of supplementary food which indirectly encourages the resumption of ovarian activity. In their detailed study, Perez et al. (1972) emphasized that full (unsupplemented) breast feeding was not a guarantee against 




Text-fig. 10. Comparison of infant feeding patterns and basal prolactin between (O) mothers ovulating within 16 weeks $(N=14)$ and $(0)$ mothers suppressing ovulation $(N=13)$ after introduction of supplementary food. Values are mean \pm s.e.m. The broken line indicates the upper limit for non-pregnant women. ${ }^{*} P<0 \cdot 01$. (From Howie et al., 1981.)

Table 1. Percentage of breast-feeding mothers giving supplements (occasional or regular) in economically advantaged, urban poor and rural groups of different countries (from W.H.O. Collaborative Study on Breast Feeding, 1979)

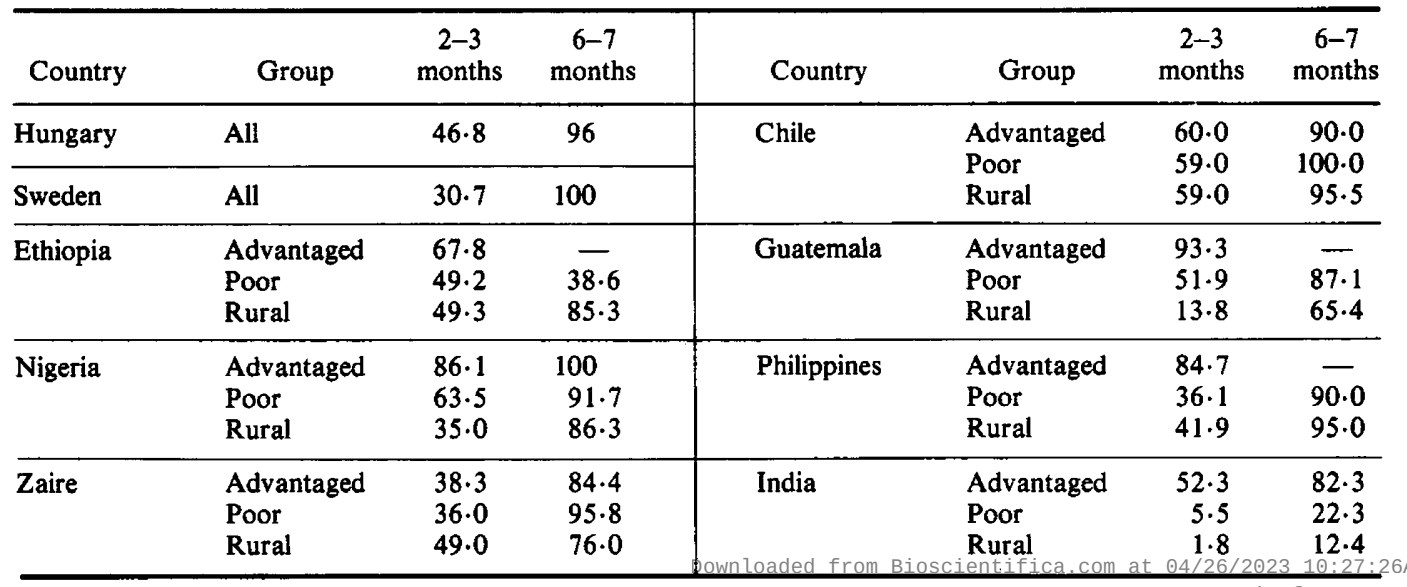


ovulation or pregnancy but they did not define the suckling frequency which constituted full breast feeding in their population. Nevertheless, it is clear that the early and regular use of supplementary food will have a detrimental effect on the contraceptive effect of breast feeding and it must be a matter of concern that the W.H.O. Collaborative Study on breast feeding found such a high use of supplementary foods among mothers from developing countries within 2-3 months post partum (Table 1).

\section{Other factors influencing lactational infertility}

It has been suggested that malnutrition may have an impact on the duration of lactational amenorrhoea, independent of breast feeding itself (Thomson, Hytten \& Black, 1975). Bongaarts (1980) has reviewed the evidence and concluded that chronic malnutrition had a relatively minor effect on fertility; for example, the median durations of amenorrhoea in low, medium and high nutrition groups from Bangladesh were 21.2, 20.4 and 20.2 months respectively (Huffman, Chowdhury, Chakbarty \& Mosley, 1978). Extreme food deprivation during famine, however, exerts a large but temporary reduction in fertility (Bongaarts, 1980).

Lunn, Prentice, Austin \& Whitehead (1980) compared two groups of breast-feeding Gambian mothers, one receiving a calorie supplement, the other receiving no such supplement. The mothers receiving the calorie supplement had lower prolactin concentrations and menstruated more quickly. This evidence suggested that maternal nutrition might have an effect on fertility but interpretation of data is made difficult by the tendency of poorly nourished mothers to breast feed for longer and suckle more frequently than well nourished mothers (Prema, Naidu \& Kumari, 1979). Future studies which investigate the effects of nutrition upon the contraceptive effects of breast feeding should have objective measures both of suckling and nutritional status.

Age has also been implicated as a factor of importance, because the duration of lactational amenorrhoea tends to be longer in older than in younger women (Jain, Hsu, Freedman \& Chang, 1970).

\section{Practical implications of lactational infertility}

Reliability of breast feeding as a contraceptive method. It has to be recognized that breast feeding cannot be relied upon as a guarantee against pregnancy for individual mothers. The place of breast feeding in fertility control has to be considered in the context of all the other factors which are pertinent to a particular population and to each of the individuals within that population. The importance of breast feeding as a method of birth spacing will depend upon the availability of alternative contraceptive methods, the willingness of the mothers to use the methods and the average duration of use of any particular method. These factors vary widely in different communities and breast feeding should be regarded as a method of fertility control which should be exploited along with, rather than instead of, alternative methods of contraception.

Nevertheless, breast feeding continues to have an important role in birth spacing throughout the world, and enthusiastic breast-feeding, characterized by frequent and energetic suckling, can exert a high degree of fertility protection, particularly during the phase of lactational amenorrhoea.

Birth spacing in developing countries. The main importance of breast feeding as a contraceptive method is in developing countries where alternative methods of family planning are used infrequently. It is clear that the modern methods of infant feeding, with the early and frequent use of supplements, will have profound implications on fertility and population growth. If there is a continuation of the trend towards early weaning in order to 'emancipate' mothers 
from the burdens of childbearing, this must be matched by increased availability and use of alternative contraceptive methods. The abandonment of prolonged breast feeding, without alternative contraception, will shorten interbirth intervals and greatly increase the burdens on individual mothers and community resources.

Breast-feeding practices have implications for infant growth, neonatal infection and birth spacing. Infant feeding policies should be designed only after recognizing the importance of all these competing factors.

Strategies of contraception. Potter, Masnick \& Gendell (1973) have pointed out that, in many communities, a contraceptive method may be used only for a finite period of time. If a contraceptive method is begun immediately after parturition, there will be an overlap between the time when the contraceptive is used and the period of post-partum anovulation when protection is not needed. By delaying the introduction of the contraceptive method, the extent of the overlap is reduced, and the potential contraceptive efficiency increased. For example, in Bangladesh, Potter et al. (1973) calculated that if the use of artificial contraception were delayed until 6 months post partum, only 1 in 200 women would have conceived by that time. More studies are required in different communities to develop strategies which exploit post-partum infertility and contraception to the best advantage.

Birth spacing in developed countries. In developed countries the majority of breast-feeding mothers will use a contraceptive method. Some of these mothers, however, dislike the inconvenience and the potential side-effects of the various methods and regard the possibility of using the birth-spacing effect of breast feeding as an attractive alternative. These mothers will have to breast feed enthusiastically and accept that the method is not absolutely reliable. More work is required to define the minimum suckling frequency and duration which are necessary to inhibit ovulation reliably but a number of guidelines can be tentatively suggested to those who wish to maximize the contraceptive effect. Mothers should feed on demand and use supplementary bottles as infrequently as possible. When it becomes nutritionally necessary for solid food to be given to the baby, this should be introduced gradually and not abruptly. Mothers should be encouraged to breast feed at night and avoid long intervals between suckling.

These guidelines lay the emphasis on suckling and require much enthusiasm on the part of the mother. Breast feeding is a complex physiological process with functions beyond those of infant nutrition alone. It is important that, in the future, the advice and support which is offered to mothers should be formulated with full realization of all the implications which breast feeding has for both maternal and child health.

\section{References}

Badraoui, M.H.H. \& Hefnawi, F. (1979) Ovarian function during lactation. In Human Ovulation, pp. 233-241. Ed. E. S. E. Hafez. Elsevier/North Holland Biomedical Press, Amsterdam.

Berman, M.L., Hanson, K. \& Hellman, I.L. (1972) Effect of breast feeding on postpartum menstruation, ovulation and pregnancy in Alaskan Eskimos. Am.J. Obstet. Gynec. 114, 524-534.

Bongaarts, J. (1980) Does malnutrition affect fecundity? A summary of evidence. Science, N.Y. 208, 564569.

Bonte, M., Akingeneye, E., Gashakamba, M., Nbarutso, E. \& Nolens, M. (1974) Influence of the socioeconomic level on the conception rate during lactation. Int. J. Fertil. 19, 97-102.

Buchanan, R. (1975) Breast-feeding-aid to infant health and fertility control. Population Reports, Series J, No. 4, 49-67.
Chen, L.C., Ahmed, S., Gesche, M. \& Mosley, W.H. (1974) A prospective study of birth interval dynamics in rural Bangladesh. Pop. Stud. 28, 277-297.

Cronin, T.J. (1968) Influence of lactation upon ovulation. Lancet ii, 422-424.

Delvoye, P., Badawi, P., Demaeged, M. \& Robyn, M. (1978) Long lasting lactation in association with hyperprolactinaemia and amenorrhoea. In Progress in Prolactin Physiology and Pathology, pp. 213-232. Eds C. Robyn \& M. Harter. Elsevier/North Holland Biomedical Press, Amsterdam.

Duchen, M. \& MeNeilly, A.S. (1980) Hyperprolactinaemia and long-term lactational amenorrhoea. Clin. Endocr. 12, 621-627.

El-Minawi, M.F. \& Foda, M.S. (1971) Post-partum lactation amenorrhea. Am. J. Obstet. Gynec. 111, 17-21. 
Gioiosa, R. (1955) Incidence of pregnancy during lactation in 500 cases. Am. J. Obstet. Gynec. 70, 162-174.

Howie, P.W., McNeilly, A.S., Houston, M.J., Cook, A. \& Boyle, H. (1981) Fertility after childbirth: effect of breast feeding on ovulation and menstruation. $\boldsymbol{B r}$. med. J. 283, 757-759.

Huffman, S.L., Chowdhury, A.M.K., Chakbarty, J. \& Mosley, W.H. (1978) Post-partum amenorrhoea: how is it affected by maternal nutritional status? Science, N.Y. 200, 1155-1157.

Jain, A.H., Hsu, T.C., Freedman, R. \& Chang, M.C. (1970) Demographic aspects of lactation and postpartum amenorrhoea. Demography 7, 255-271.

Kamal, I., Hefnawi, F., Ghoneim, M., Talaat, M., Younis, N., Tagui, A. \& Abdalla, M. (1969) Clinical biochemical and experimental studies on lactation. I. Lactation pattern in Egyptian women. Am.J. Obstet. Gynec. 105, 314-323.

Knodel, J. (1977) Breast feeding and population growth. Science, N.Y. 198, 1111-1115.

Konner, M. \& Worthman, C. (1980) Nursing frequency, gonadal function and birth spacing among !Kung hunter gatherers. Science, N.Y. 207, 788-791.

Lass, P.M., Smelser, J. \& Kurzrok, R. (1938) Studies relating to time of human ovulation. iii. During lactation. Endocrinology 23, 39-43.

Lunn, P.G., Prentice, A.G., Austin, S. \& Whitehead, R.G. (1980) Influence of maternal diet on plasma prolactin levels during lactation. Lancet $\mathrm{i}, 623-625$.

McKeown, T. \& Gibson, J. A. (1954) A note on menstruation and conception during lactation. $J$. Obstet. Gynaec. Br. Emp. 61, 824-826.

McNeilly, A.S. (1979) Effects of lactation on fertility. Br. med. Bull. 35, 151-154.

McNeilly, A.S., Howie, P.W. \& Houston, M.J. (1980) Relationship of feeding patterns, prolactin and resumption of ovulation post-partum. In Research Frontiers in Fertility Regulation, pp. 102-116. Eds G. I. Zatuchni, M. H. Labbok \& J. J. Sciarra. Harper \& Row, New York.
Morley, D. (1977) Biosocial advantages of an adequate birth interval. J. biosoc. Sci., Suppl. 4, 69-81.

Perez, A., Vela, P., Masnick, G.S. \& Potter, R.G. (1972) First ovulation after childbirth: the effect of breast feeding. Am. J. Obstet. Gynec. 114, 1041-1047.

Potter, R.G., New, M.L., Wyon, J.B. \& Gordon, J.E. (1965) Applications of field studies to research on physiology of human reproduction. Lactation and its effects upon birth intervals in eleven Punjab villages, India. J. Chron. Dis. 18, 1125-1140.

Potter, R.G., Masnick, G.S. \& Gendell, M. (1973) Postamenorrhoeic versus post-partum strategies of contraception. Demography 10, 99-112.

Prema, K., Naidu, A.N. \& Kumari, S.N. (1979) Lactation and fertility. Am. J. clin. Nutr. 32, 1298-1303.

Rolland, R., Lequin, R.M., Schellekens, L.A. \& de Jong, F.A. (1975) The role of prolactin in the restoration of ovarian function during the early post-partum period in the human female. I. Study during physiological lactation. Clin. Endocr. 4, 15-25.

Rosa, F.W. (1975) The role of breast feeding in family planning. WHO Protein Advisory Group Bull. 5, No. 3, 5-10.

Sharman, A. (1951) Menstruation after childbirth. $J$. Obstet. Gynaec. Br. Emp. 58, 440-445.

Thomson, A., Hytten, F.E. \& Black, A.E. (1975) Lactation and reproduction. Bull. Wld Hlth Org. 52, 337-349.

Tietze, C. (1968) Fertility after discontinuation of intrauterine and oral contraception. Int. J. Fertil. 13, 385-389.

Topkins, P. (1943) The histologic appearance of the endometrium during lactation amenorrhea and its relationship to ovarian function. $A m$. J. Obstet. Gynec. 45, 48-58.

Udesky, I.C. (1950) Orulation in lactating women. Am. J. Obstet. Gynec. 59, 843-848.

van Ginneken, J.K. (1977) The chance of conception during lactation. J. biosoc. Sci., Suppl. 4, 41-54. 